\title{
Pyogenic granuloma of the descending colon
}

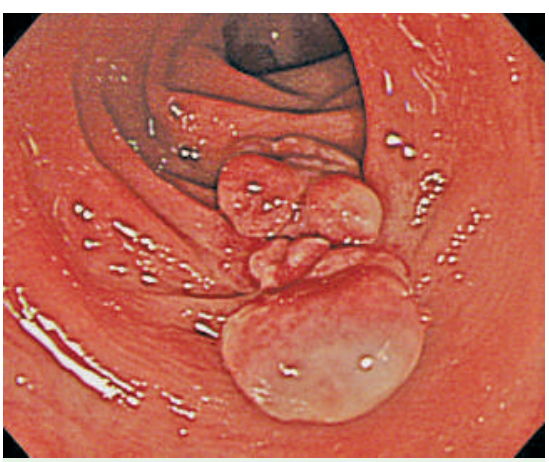

Fig. 1 Conventional colonoscopy revealed a light-red, sessile lesion, about $15 \mathrm{~mm}$ in diameter, which consisted of nodules of various sizes and which was covered with white exudate.

A 59-year-old woman who was known to have large hepatic cysts presented with a positive fecal occult blood test. Her physical examination was unremarkable, and laboratory testing revealed no abnormalities. A double-contrast barium study showed a round, radiolucent area in the descending colon. Colonoscopy revealed a light-red, sessile lesion, about $15 \mathrm{~mm}$ in diameter, which consisted of variouslysized nodules covered with white exudate ( Fig. 1). The rest of the colonic mucosa was unremarkable. When the specimen was biopsied massive bleeding occurred, suggesting that the lesion was hypervascular. Histological examination of the biopsy specimen showed proliferation of capillaries.

The lesion was resected and the large hepatic cysts were drained during the same laparoscopic procedure. Histologically, the surface was found to be covered by foci of regenerating epithelium ( $\bullet$ Fig. 2). High-power magnification showed that the tumor was composed of numerous capillaries which were lined with plump endothelial cells, with an edematous stroma containing acute and chronic inflammatory cell infiltrates ( Fig.3). There were also so-called "satellite" lesions [1] in the muscularis propria layer and in the subserosa ( Fig. 4). On the basis of these findings, the tumor was diagnosed as a pyogenic granuloma. One year later, no evidence of recurrence was found on follow-up colonoscopy, and she reported no gastrointestinal symptoms.

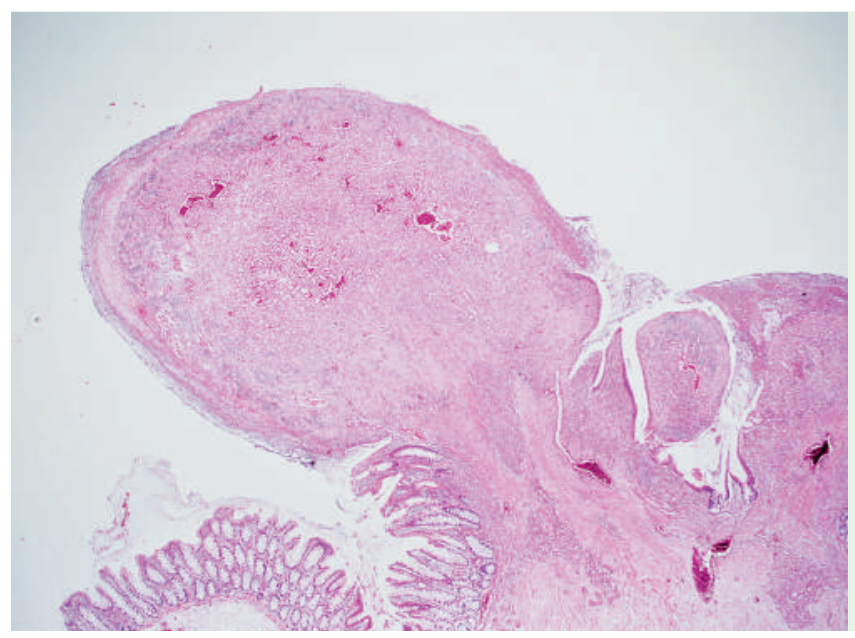

Fig. 2 Histologically, the surface of the colonic lesion was covered by foci of regenerating epithelium.

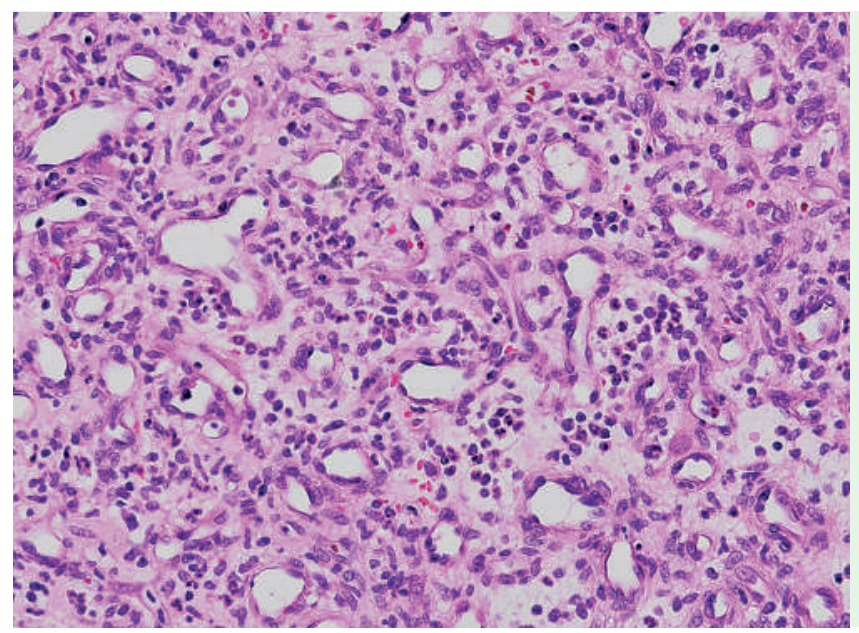

Fig. 3 High-power magnification showed that the tumor was composed of numerous capillaries which were lined with plump endothelial cells, with an edematous stroma containing acute and chronic inflammatory cell infiltrates.

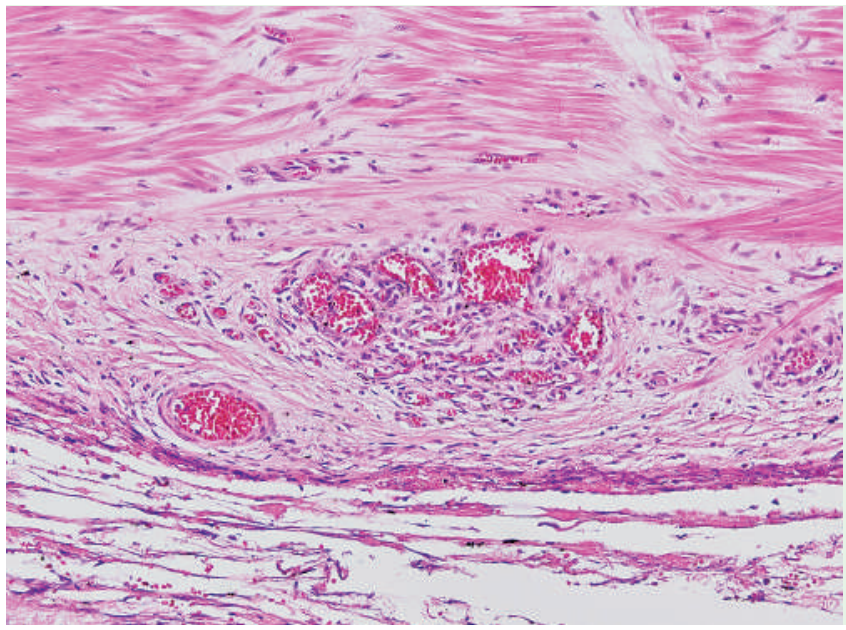

Fig. 4 A satellite lesion was found in the subserosal layer.

Pyogenic granuloma is a benign lesion, although recurrence has been reported [2]. It occurs extremely rarely in the gastrointestinal tract, and only 20 cases have been reported in the literature [3-5]. With respect to treatment, both surgical and en- doscopic resection methods have been described. Because this patient also required treatment for her large hepatic cysts, laparoscopic resection was the best option in this case. To our knowledge, this is the first report of pygenic granuloma in 
the descending colon and the case is also notable in that it was associated with satellite lesions.

Endoscopy_UCTN_Code_CCL_1AD_2AC

Endoscopy_UCTN_Code_CCL_1AD_2AD

T. Nakaya ${ }^{1}$, T. Tokunaga ${ }^{1}$, S. Aono ${ }^{1}$, S. Kobari ${ }^{1}$, S. Tounou ${ }^{1}$, Y. Magata ${ }^{1}$, K. Utsunomiya², K. Hase ${ }^{2}$

${ }^{1}$ Department of Endoscopy, Self Defense Force Central Hospital, Tokyo, Japan

2 Department of Surgery, Self Defense Force Central Hospital, Tokyo, Japan

\section{References}

1 Warner J, Jones EW. Pyogenic granuloma reccurring with multiple satellites: a report of 11 cases. Br J Dermatol 1968; 80: 218-227

2 Patrice SJ, Wiss K, Mulliken JB. Pyogenic granuloma (lobular capillary hemangioma): a clinicopathologic study of 178 cases. Pediatr Dermatol 1991; 8: 267-276

3 Hirakawa K, Aoyagi K, Yao T et al. A case of pyogenic granuloma in the duodenum: successful treatment by endoscopic snare polypectomy. Gastrointest Endosc 1998; 47: $538-540$

4 Chen TC, Lien JM, Ng KF et al. Multiple pyogenic granulomas in sigmoid colon. Gastrointest Endosc 1999; 49: 257 - 259

5 Okada N, Matsumoto T, Kurahara $K$ et al. Pyogenic granuloma of the esophagus treated by endoscopic removal. Endoscopy 2003; 35: 375
Bibliography

DOI $10.1055 / \mathrm{s}-2007-966485$

Endoscopy 2007; 39: 259-260

(c) Georg Thieme Verlag KG Stuttgart · New York . ISSN 0013-726X

Corresponding author

\section{T. Tokunaga, MD}

1-2-24 Ikejiri

Setagaya

Tokyo 154-8532

Japan

Fax: +81-3-54933798

tokunaga_tetsuzi@yahoo.co.jp 